\title{
BMJ Open Nature and type of patient-reported safety incidents in primary care: cross- sectional survey of patients from Australia and England
}

\author{
Andrea L Hernan (D , , Sally J Giles, ${ }^{2}$ Andrew Carson-Stevens (D) , ${ }^{3,4}$ Mark Morgan, ${ }^{5}$ \\ Penny Lewis, ${ }^{6}$ James Hind, ${ }^{2}$ Vincent Versace ${ }^{1}$
}

To cite: Hernan AL, Giles SJ, Carson-Stevens A, et al. Nature and type of patient-reported safety incidents in primary care: cross-sectional survey of patients from Australia and England. BMJ Open 2021;11:e042551. doi:10.1136/ bmjopen-2020-042551

- Prepublication history and supplemental material for this paper is available online. To view these files, please visit the journal online (http://dx.doi. org/10.1136/bmjopen-2020042551).

Received 08 July 2020 Revised 08 February 2021 Accepted 01 April 2021
Check for updates

(c) Author(s) (or their employer(s)) 2021. Re-use permitted under CC BY-NC. No commercial re-use. See rights and permissions. Published by BMJ.

For numbered affiliations see end of article.

Correspondence to

Dr Andrea L Hernan;

andrea.hernan@deakin.edu.au

\section{ABSTRACT}

Background Patient engagement in safety has shown positive effects in preventing or reducing adverse events and potential safety risks. Capturing and utilising patientreported safety incident data can be used for service learning and improvement.

Objective The aim of this study was to characterise the nature of patient-reported safety incidents in primary care. Design Secondary analysis of two cross sectional studies. Participants Adult patients from Australian and English primary care settings.

Measures Patients' self-reported experiences of safety incidents were captured using the validated Primary Care Patient Measure of Safety questionnaire. Qualitative responses to survey items were analysed and categorised using the Primary Care Patient Safety Classification System. The frequency and type of safety incidents, contributory factors, and patient and system level outcomes are presented.

Results A total of 1329 patients $(n=490$, England; $\mathrm{n}=839$, Australia) completed the questionnaire. Overall, $5.3 \%(n=69)$ of patients reported a safety incident over the preceding 12 months. The most common incident types were administration incidents $(n=27,31 \%)$ (mainly delays in accessing a physician) and incidents involving diagnosis and assessment ( $n=16,18.4 \%)$. Organisation of care accounted for $27.6 \%(n=29)$ of the contributory factors identified in the safety incidents. Staff factors $(n=13,12.4 \%)$ was the second most commonly reported contributory factor. Where an outcome could be determined, patient inconvenience $(n=24,28.6 \%)$ and clinical harm $(n=21,25 \%)$ (psychological distress and unpleasant experience) were the most frequent.

Conclusions The nature and outcomes of patientreported incidents differ markedly from those identified in studies of staff-reported incidents. The findings from this study emphasise the importance of capturing patientreported safety incidents in the primary care setting. The patient perspective can complement existing sources of safety intelligence with the potential for service improvement.

\section{INTRODUCTION}

Involving patients in safety incident prevention and harm reduction activities has gained
Strengths and limitations of this study

- This research addressed important gaps in knowledge about patient reporting of safety incidents in primary care.

- Our study described and categorised patientreported safety incidents in diverse settings of England and Australia.

- The study used a validated tool to collect qualitative data about patient perceptions of safety incidents.

- Categorisation of safety incidents was performed by an expert panel using a structured framework called the Primary Care Patient Safety Classification.

- The study was limited by lack of detail in some patient incident reports.

traction over the past decade. Patient engagement in safety has shown positive effects in preventing or reducing adverse events, and increasing perception and awareness of potential safety risks. ${ }^{1-8}$ Patients' observations and concerns play a critical and fundamental role towards the planning and the delivery of healthcare, ensuring their safety. ${ }^{9-13}$ Patients can offer a different perspective to safety incidents and risks, and often identify different types of safety incidents and outcomes than staff. $^{3} 712$ Capturing and utilising patientreported safety incident data can be used for service learning and improvement. Indeed, innovative and unique change ideas and interventions for making the health systems safer for patients have been implemented successfully using patient-reported data. ${ }^{14} 15$

However, most of the evidence describing the nature of patient-reported safety incidents has originated from the hospital setting, ${ }^{16}$ with primary care considered an emerging research area. ${ }^{17-26}$

A small number of studies have described the frequency of patient-reported safety incidents or errors, and harm in primary 
care. $^{27-34}$ There was great variability in terms of the studies methodologies, and definitions used for safety incidents, errors and harm. Studies evaluating frequency of safety incidents ranged between $7.6 \%$ and $45 \% .{ }^{28} 303134$ Studies examining the frequency of error or experience of adverse event ranged between 9\% and 20\%. 293233 One study has categorised the level of harm with $41.7 \%$ of patients reporting a lot or severe harm from diagnostic mistakes, and $45.7 \%$ experiencing a lot or severe harm from treatment mistakes. ${ }^{28}$ The level of harm in the remaining studies occurred in between $7 \%$ and $29 \%$ of cases. $^{31} 33$

Some patient-reported contributing factors to safety incidents have also been published including communication, the patient-provider relationship, access to care, care organisation, teamwork, information flow, continuity of care and patient-related factors (eg, medication non-adherence). ${ }^{27} 293135-40$

We aimed to contribute to the developing evidence base by characterising the nature of patient-reported safety incidents in primary care. Secondary analysis of data collected from two studies investigating contributory factors to safety incidents in Australian and English primary care settings ${ }^{154142}$ are reported in this paper.

\section{METHODS}

The sampling and data collection strategies for the two studies investigating patient safety in primary care were similar, and used the same anonymous and validated questionnaire developed by researchers $\mathrm{ALH}$ and $\mathrm{SJG}^{41}$ in two locations. A detailed summary of the methods for study 1 and 2 have previously been described elsewhere ${ }^{154142}$ and are briefly described below.

\section{Study 1: validation study of the primary care patient measure of safety tool \\ Sampling frame}

Nine primary care practices from within the Greater Manchester area agreed to participate in a study to determine the validity and reliability of the Primary Care Patient Measure of Safety (PC PMOS) ${ }^{41}$ questionnaire between April and September 2016. Practices were recruited using purposive and snowball sampling with the intention of ensuring a diverse range of participants with respect to practice size, practice location and deprivation levels. Online supplemental appendix 1 contains practice characteristic information.

\section{Data collection}

Adult patients were provided the PC PMOS questionnaire by practice administration staff or by direct approach from members of the research team when presenting for their appointment. Participation was voluntary. Patients who agreed to participate returned the questionnaire before or after the consultation or by post. Recruitment was considered achieved when a minimum of 50 patients from each of the nine respective general practices returned the questionnaire.

\section{Study 2: feasibility study of an intervention using patient feedback for safety improvement in primary care \\ Sampling frame}

Six primary care practices from the south-west region of Victoria, Australia participated in a study investigating the feasibility of a patient feedback for safety improvement intervention during 2018-2019. ${ }^{15}$ A mix of small and large practices were purposively recruited into the study. The practices were relatively homogeneous in terms of population characteristics. ${ }^{43}$ Online supplemental appendix 2 contains practice characteristic information.

\section{Data collection}

Every adult (over 18 years) presenting for their appointment was invited by the practice receptionist to complete the PC PMOS over a 3-week period. Patients returned their surveys via a secure survey return box in the practice waiting room. Patient consent was implied by the completion and return of the PC PMOS questionnaire. A plain language statement acted as the coversheet for the PC PMOS questionnaire.

\section{Questionnaire}

Patient-reported safety incidents were collected using the PC PMOS tool. ${ }^{41}$ The PC PMOS is a 28-item survey covering nine latent conditions in the primary care environment influencing safety incidents, such as access to care, communication, information flow, organisation care and planning and task performance. Basic demographic data on patient age, gender and number of visits to the general practice in the previous 12 months were also collected.

The PC PMOS contains six free-text questions for patients to report any safety incidents, problems or harms they had experienced in primary care. These questions were adapted from the Patient Incident Reporting Tool (PIRT) developed for research concerning patient involvement in safety in the hospital setting. ${ }^{4-46}$ The questions were: (1) Have you experienced something that you thought was a safety concern or issue in the last 12 months at this practice? (yes or no); (2) If yes, please tell us what happened in as much detail as you can? (free text); (3) Why do you feel this was a 'safety concern' for you? (free text); (4) What do you think could be done to stop this from happening again to you or other patients, in the future? (free text); (5) Do you think it would have been possible to have stopped your experience from happening? (Five point Likert scale with response options: 'definitely yes', 'probably yes', 'probably not', 'definitely not' and 'don't know'); and (6) On a scale of 1 to 10 how serious do you think your 'safety concern' was? (score of 1 being 'not serious at all' and 10 being 'extremely serious'). Questions 1 to 4 and 6 on the PIRT were selfderived using an expert panel consisting of patients, clinicians, and researchers who developed questions that 
were deemed meaningful, relevant and patient-friendly. ${ }^{45}$ Question 5 is a standardised risk preventability question used in previous studies investigating safety incidents. ${ }^{47} 48$ There was an 'additional comments' question with a freetext response at the end of the questionnaire which could also capture self-reported safety incidents (online supplemental appendix 3).

\section{Data analysis}

Data from study 1 and 2 were extracted verbatim from the PC PMOS questionnaires to a secure encoded Microsoft Excel database. Data were then cleaned and categorised by the authors (ALH and SJG) using the Primary Care Patient Safety Classification (PISA) System. ${ }^{49}$ The PISA System was empirically developed using patient safety incident reports maintained by the National Health Service (NHS) in England and Wales, namely the National Reporting and Learning System.

Each report underwent data coding using multiaxial frameworks to describe incident types (primary and contributory), potential contributory factors, incident outcomes and harm severity. ${ }^{49}{ }^{50}$ Primary incidents included those proximal (chronologically) to the patient outcome, whereas contributory incidents included those that contributed to the occurrence of another incident. Contributory factors to a safety incident are defined as 'issues that did not directly cause, but contributed to, the occurrence of an incident'. ${ }^{49}$ Multiple codes for incident type, contributory factor and incident outcome were applied to each report where necessary. This process was both deductive and inductive. Codes from the framework were used where appropriate and inductive codes were generated when there was no code available in the framework. The codes were applied systematically and chronologically according to recursive incident analysis rules developed by the Australian Patient Safety Foundation. ${ }^{51}$ This permitted modelling of the steps preceding and leading to primary incidents (eg, contributory incidents and factors, which, in turn, resulted in patient outcomes). Figure 1 illustrates how the recursive model for incident analysis works in practice.

An international expert panel was devised to review the patient-reported safety incident data and help form consensus on the final incident, contributory factors and outcome category codes. The multidisciplinary panel consisting of patient safety academic clinicians $(n=4)$ and patient representatives $(n=2)$ were recruited using the study team's known networks in the patient safety in primary care field. Expert panel members were asked to objectively review the codes and provide a response; 'agree', 'disagree' or 'unsure'. A justification and an alternative code was suggested by the expert when 'disagree' or 'unsure' options were selected.

When the patient-reported data did not correspond with the PISA System codes, specific self-derived codes were developed by authors ALH and SJG and the expert panel members. When there was not enough information contained in the patient incident report to accurately classify an incident, contributory factor, or outcome, a specific code was used (eg, unknown, insufficient detail, unclear).

Once coding was completed by the expert panel, two authors (ALH and SJG) reviewed the codes assigned to each patient-reported safety incident. Interrater reliability was assessed by calculating kappa scores for ALH and SJG and a third coder. Kappa scores indicated substantial agreement for the incident type, contributory factor and outcome codes $(\mathrm{k}=0.867, \mathrm{k}=0.828$, and $\mathrm{k}=0.965$, respectively) ${ }^{52}$

The final codes were determined by ALH and SJG using consensus of reviewer agreement, and their explanations and comments corresponding to particular patientreported safety incidents.

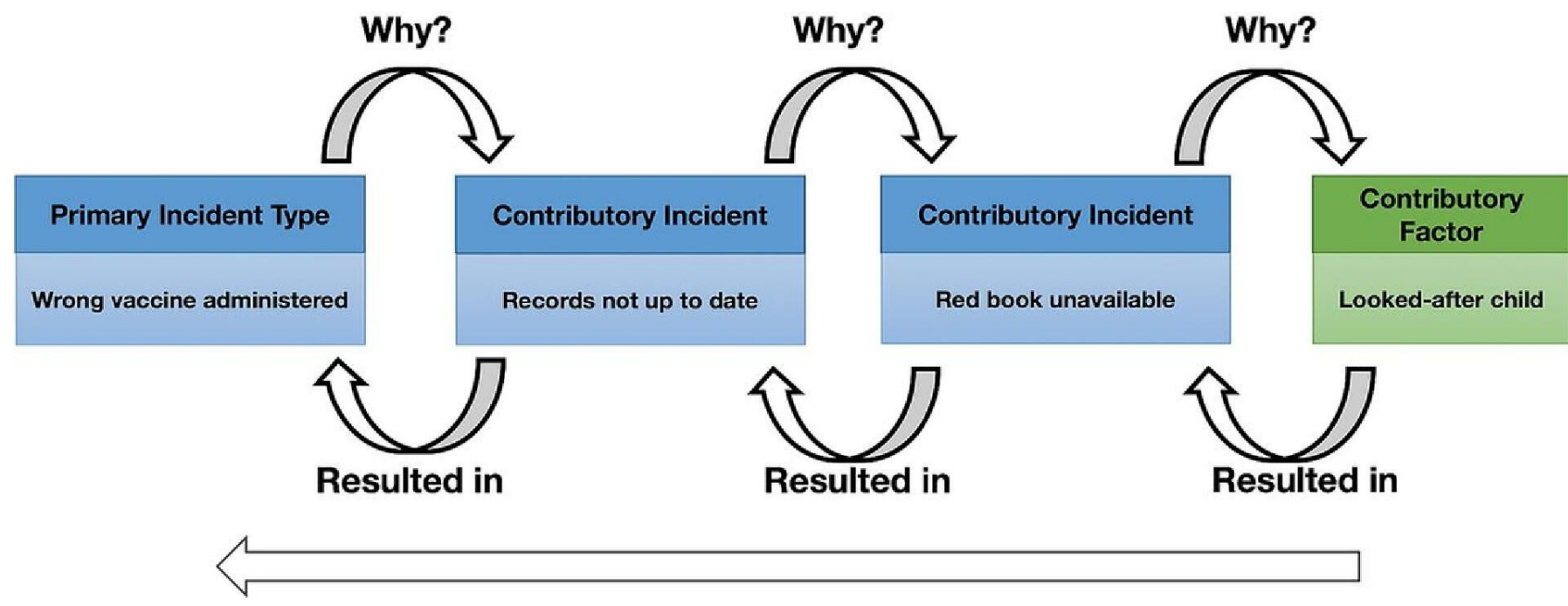

Time

Figure 1 Example of codes from the Primary Care Patient Safety (PISA) Classification System using the recursive model for incident analysis. Reproduced with permission from the authors. Originally published by Carson-Stevens et al. ${ }^{70}$ 
Descriptive summaries were generated to describe the frequency of incident types, contributory factors and incident outcomes (type of harm). Quantitative data were analysed using IBM SPSS Statistics V.23.

Descriptive statistics for the preventability and seriousness of the safety incident were generated. Patients self-reported data for the preventability and seriousness of the safety incident questions. Preventability categories were collapsed into 'preventable' and 'not preventable' categories. ${ }^{47}$ ' The continuous seriousness of the incident scale was classified into three categories 'not serious at all' (scores 1-3), 'moderately serious' (scored 4-7) and 'extremely serious' (8-10). A serious and preventable variable was created which included incidents that were classified as 'preventable' and 'extremely serious'. ${ }^{53}$

Patient-related factors associated with reporting a safety incident were explored. $\mathrm{P}$ values are based on $\chi^{2}$ test for the categorical variable (gender), and independent sample $t$ tests for the continuous variables (age, frequency of visits, mean PC PMOS score).

The frequency of safety incidents was calculated using the number of incident reports provided from the total sample of questionnaires returned.

\section{Patient and public involvement}

Two patient representatives formed part of the expert panel who reviewed the patient-reported safety incident data and helped form consensus on the final incident, contributory factors and outcome category codes.

\section{RESULTS}

A total of $n=1329$ patients completed the PC PMOS questionnaire in both Study 1 and 2 ( $n=490$ Study $1, n=839$ Study 2). From study 1 and 2, there were a total of $n=69$ patient-reported safety incidents $(\mathrm{n}=41$ Study $1, \mathrm{n}=28$ Study 2). 5.3\% of patients reported a safety incident over the preceding 12 months. Patient demographic characteristics are provided in table 1.

Forty-one safety incidents were revealed by question 1: 'Have you experienced something that you thought was a safety concern or issue in the last 12 months at this practice?', and 28 incidents were described in 'Other Comments' section of the questionnaire.

The patient-reported safety incidents were classified across eight categories (table 2). Nearly one-third ( $n=27)$ of the reports related to administration incidents, of which the majority concerned delays in patients accessing a physician $(\mathrm{n}=21,24.1 \%)$. The remaining six incidents (6.9\%) concerned errors in communication of information. Availability of appointments and long delays to see preferred physician were commonly reported. In some cases, patients reported delays in accessing care by up to 3 weeks and often presented to the clinic without an appointment for urgent care:

\begin{tabular}{|c|c|c|c|c|}
\hline & & $\begin{array}{l}\text { Safety } \\
\text { incident } \\
\text { reported }\end{array}$ & $\begin{array}{l}\text { No safety } \\
\text { incident } \\
\text { reported }\end{array}$ & $P$ value \\
\hline \multicolumn{5}{|l|}{$\begin{array}{l}\text { Gender } \\
(n=1307)\end{array}$} \\
\hline Male & n (\%) & $15(21.7)$ & 389 (31.4) & 0.090 \\
\hline Female & $\mathrm{n}(\%)$ & 54 (78.3) & 849 (68.6) & \\
\hline \multirow{2}{*}{$\begin{array}{l}\text { Age (years) } \\
(n=1284)\end{array}$} & $\mathrm{n}$ & 68 & 1216 & 0.459 \\
\hline & $\begin{array}{l}\text { Mean } \\
\text { (SE) }\end{array}$ & $48.96(2.2)$ & $52.83(1.2)$ & \\
\hline \multirow{2}{*}{$\begin{array}{l}\text { No of visits } \\
\text { to general } \\
\text { practice* } \\
(n=1253)\end{array}$} & $\mathrm{n}$ & 66 & 1187 & $0.006 \dagger$ \\
\hline & $\begin{array}{l}\text { Mean } \\
\text { (SE) }\end{array}$ & $12(1.7)$ & $7(0.23)$ & \\
\hline \multirow{2}{*}{$\begin{array}{l}\text { PC PMOS } \\
\text { score } \neq \\
(n=1323)\end{array}$} & $n$ & 69 & 1254 & $<0.001 \dagger$ \\
\hline & $\begin{array}{l}\text { Mean } \\
\text { (SE) }\end{array}$ & $3.8(0.07)$ & $4.2(0.02)$ & \\
\hline
\end{tabular}

The denominator for some variables is less than the total sample as there were some missing data.

*Number of visits to the general practice in the previous 12 months.

†Statistically significant difference.

†PC PMOS score uses 1-5 scale with lower scores indicating poorer safety.

PC PMOS, Primary Care Patient Measure of Safety.

Unable to get appointment after referral from hospital as a matter of urgency. Had to stand outside at 8 AM to make an appointment. (Study 1)

The second most commonly reported incident type was diagnosis and assessment $(n=16,18.4 \%)$. Errors in the process of assessing a patient were often reported $(n=6$, $6.9 \%)$. Patients described incidents where they believed physicians had not taken their health concern seriously or had not taken the time to adequately assess their condition.

The contributory factors to the patient-reported safety incidents were classified across seven categories (table 3). Organisation of care accounted for $27.6 \% \quad(n=29)$ of the contributory factors identified in the safety incidents. Continuity of care and staff behaviour were most commonly described in this category. Problems of continuity of care within primary care and between different settings were reported:

In [hospital] for major operation, on seeing my doctor [GP] when I came out no information was available to him. (The GP) was not aware which medication was prescribed. (Study 1)

Staff behaviour related to inappropriate conduct or performance, mainly concerning patient communication and interaction:

A lot of doctors tend to run late, yet if a patient is a couple of minutes late, we have had an instance when 


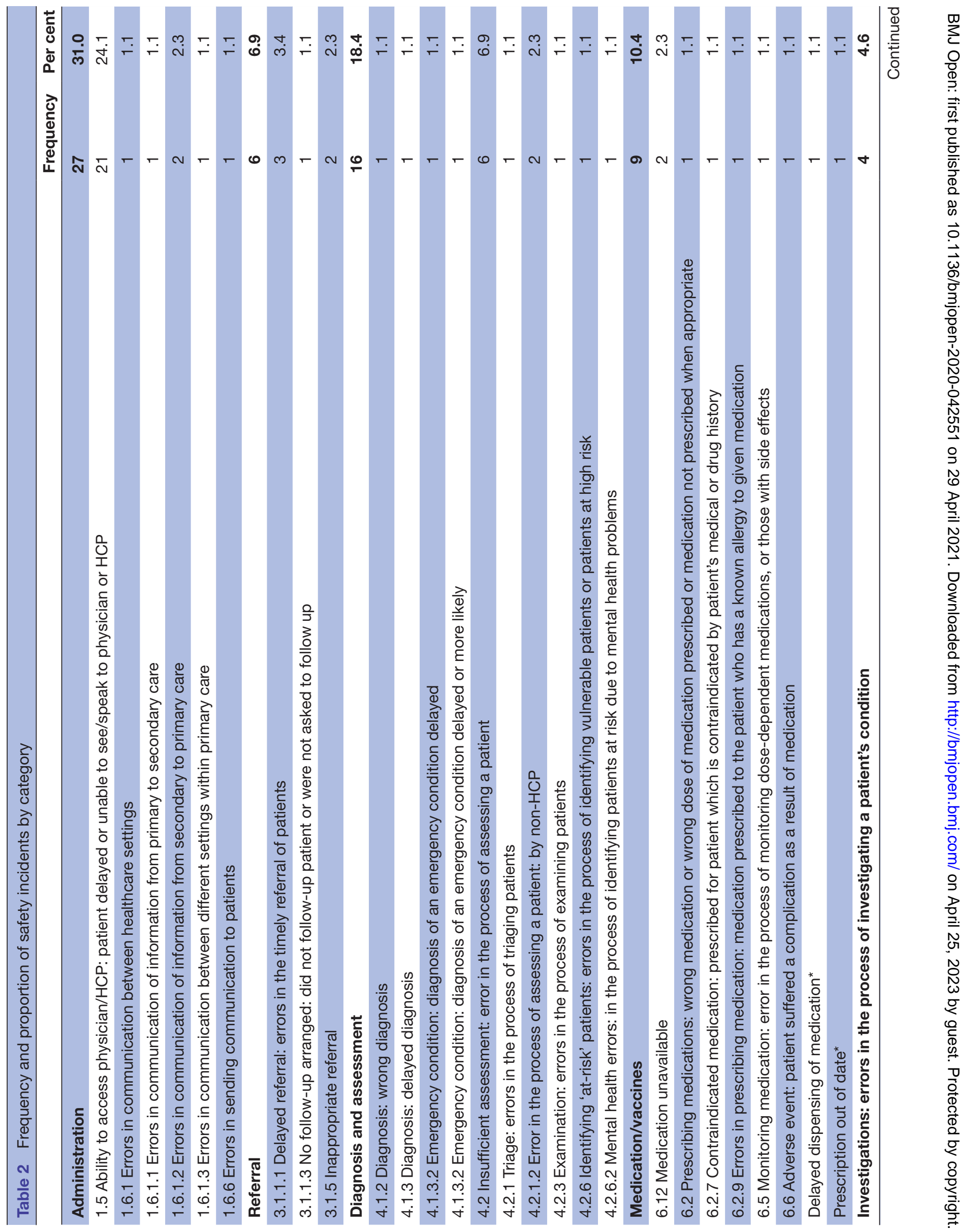




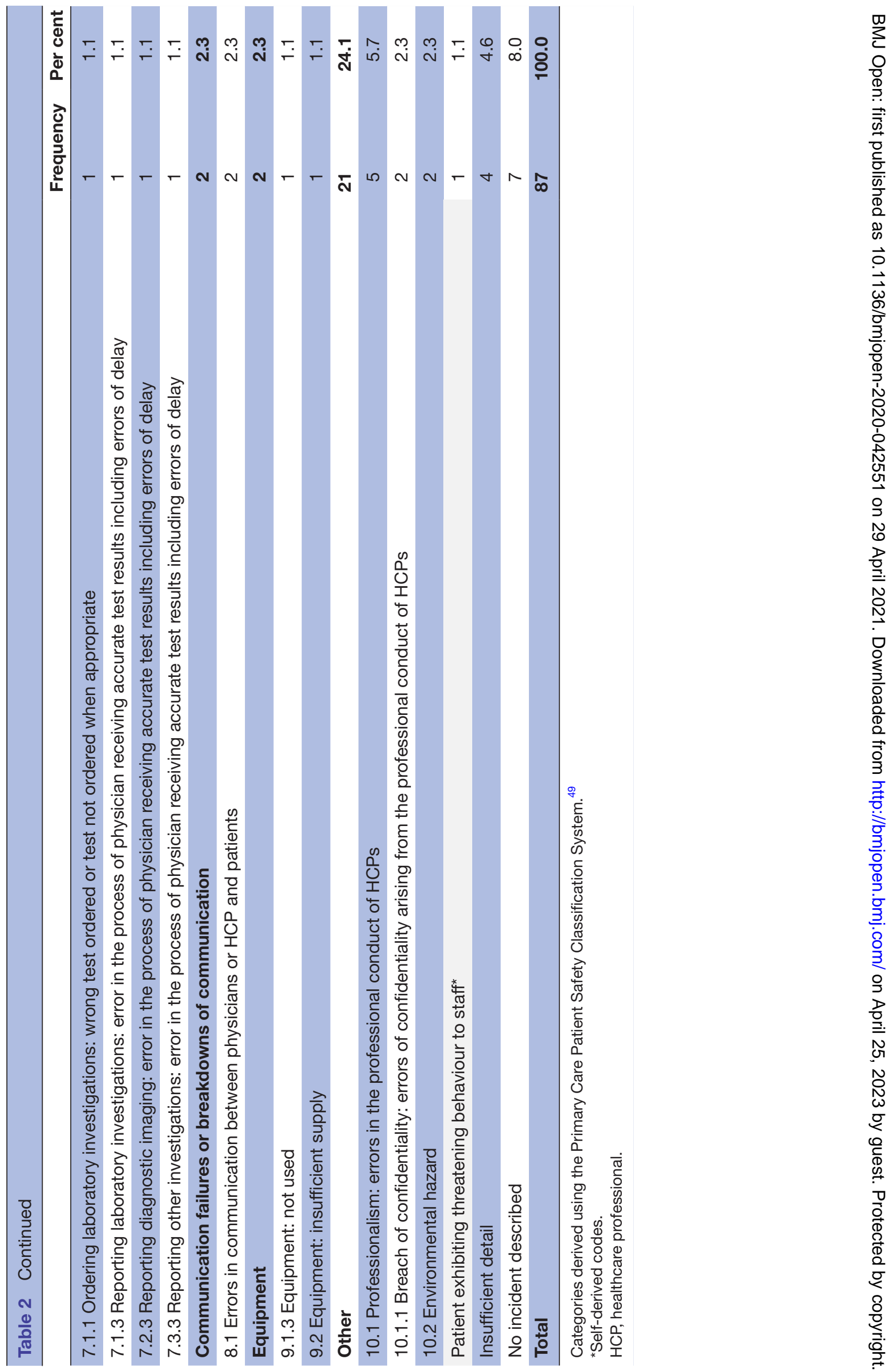




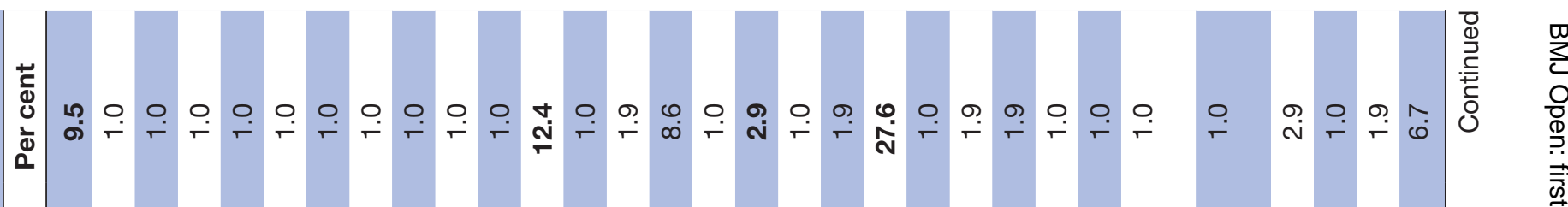

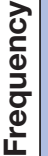

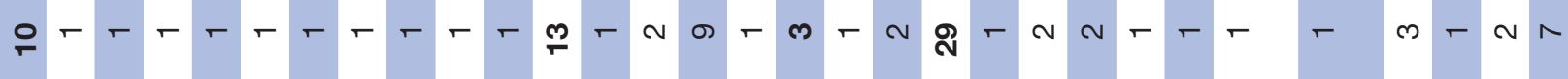

(2)

to

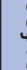

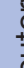

垔

(

政

高

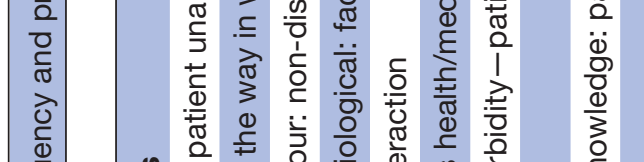

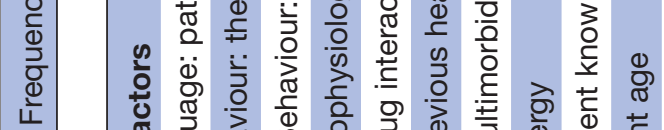

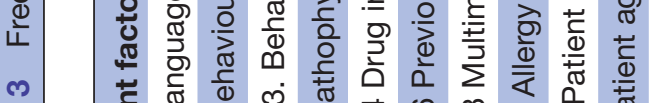
苟苟

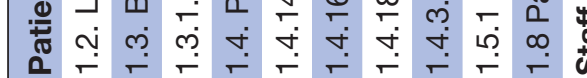
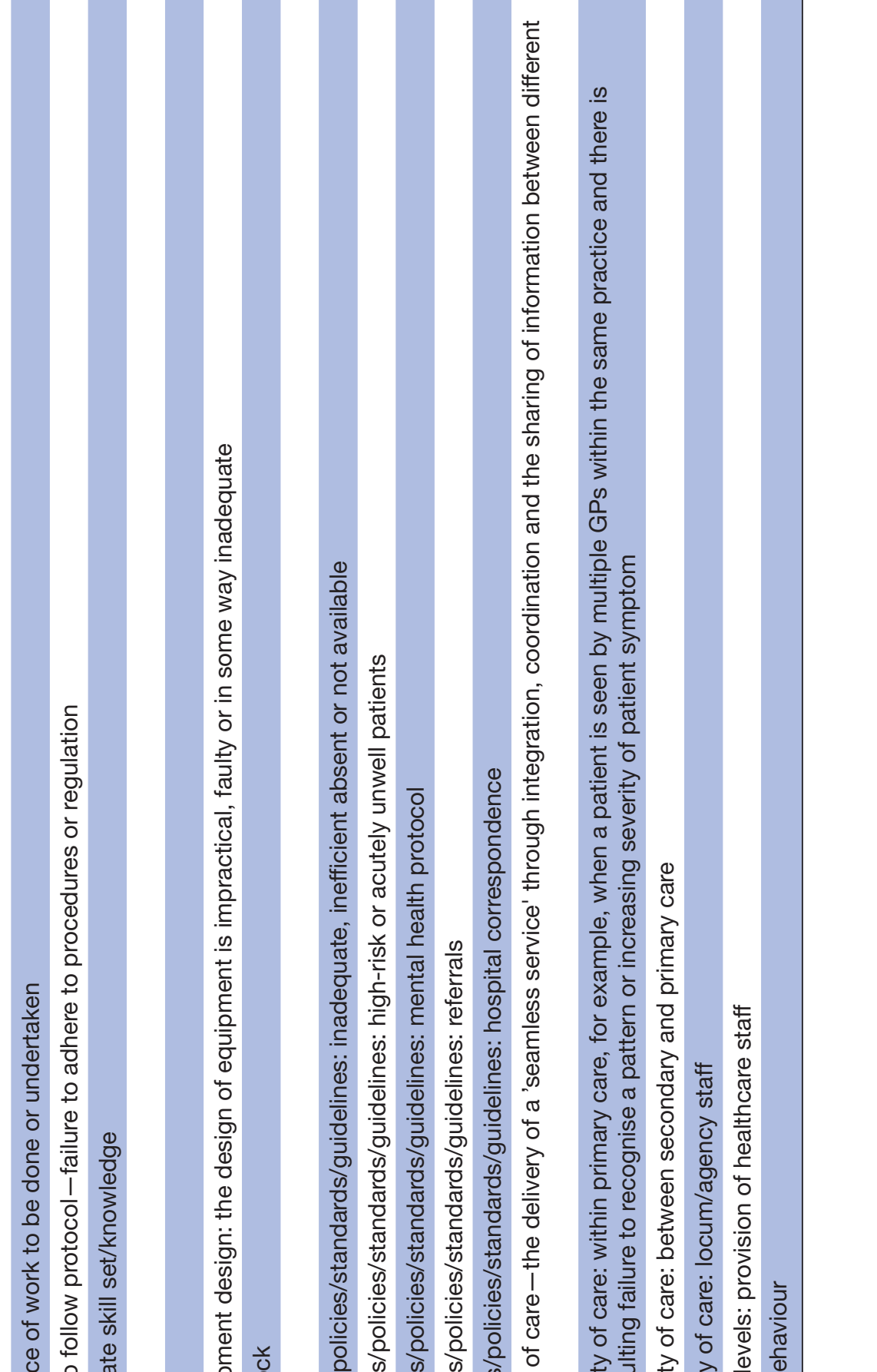

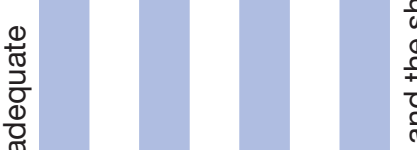

달

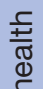

ฮั

$\frac{\frac{10}{\circ}}{\frac{\pi}{20}}$

帘

苛

하욤

䔡 $\frac{\varrho}{\overline{0}}$

章

垔

离.

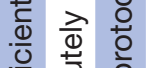

을 을

要

흘

बे

:

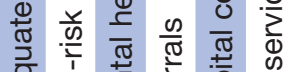

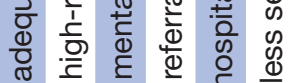

告

要离

船

을 을 응

के के के को के

की

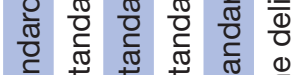

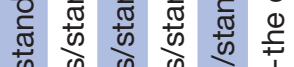

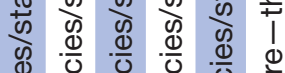

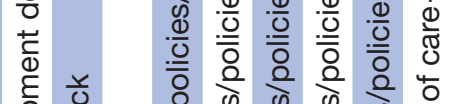

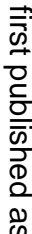

$\overrightarrow{0}$

$\overrightarrow{\vec{\omega}}$

$\frac{0}{3}$

$\stackrel{0}{9}$

స్․․

$\dot{+}$

ज

잉

กั

을.

옳

¿ั

产

\%ั0

$\stackrel{\circ}{\overrightarrow{0}}$

言

के

응

宁.

ब.

है.

×

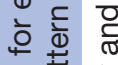

क

옹 중

$>0$ क क

穷.

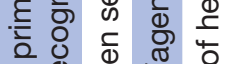

ᄃ

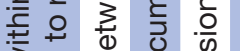

造产

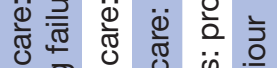

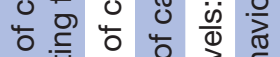

造

응 $\frac{2}{\omega} \frac{2}{\omega} \frac{2}{0} \frac{0}{0}$

굴

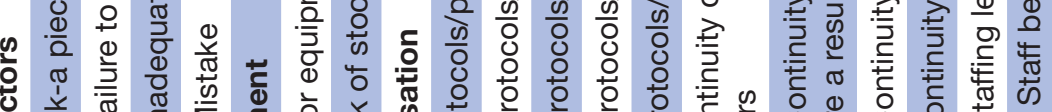

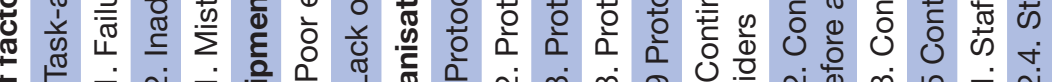

ז

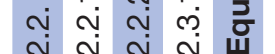




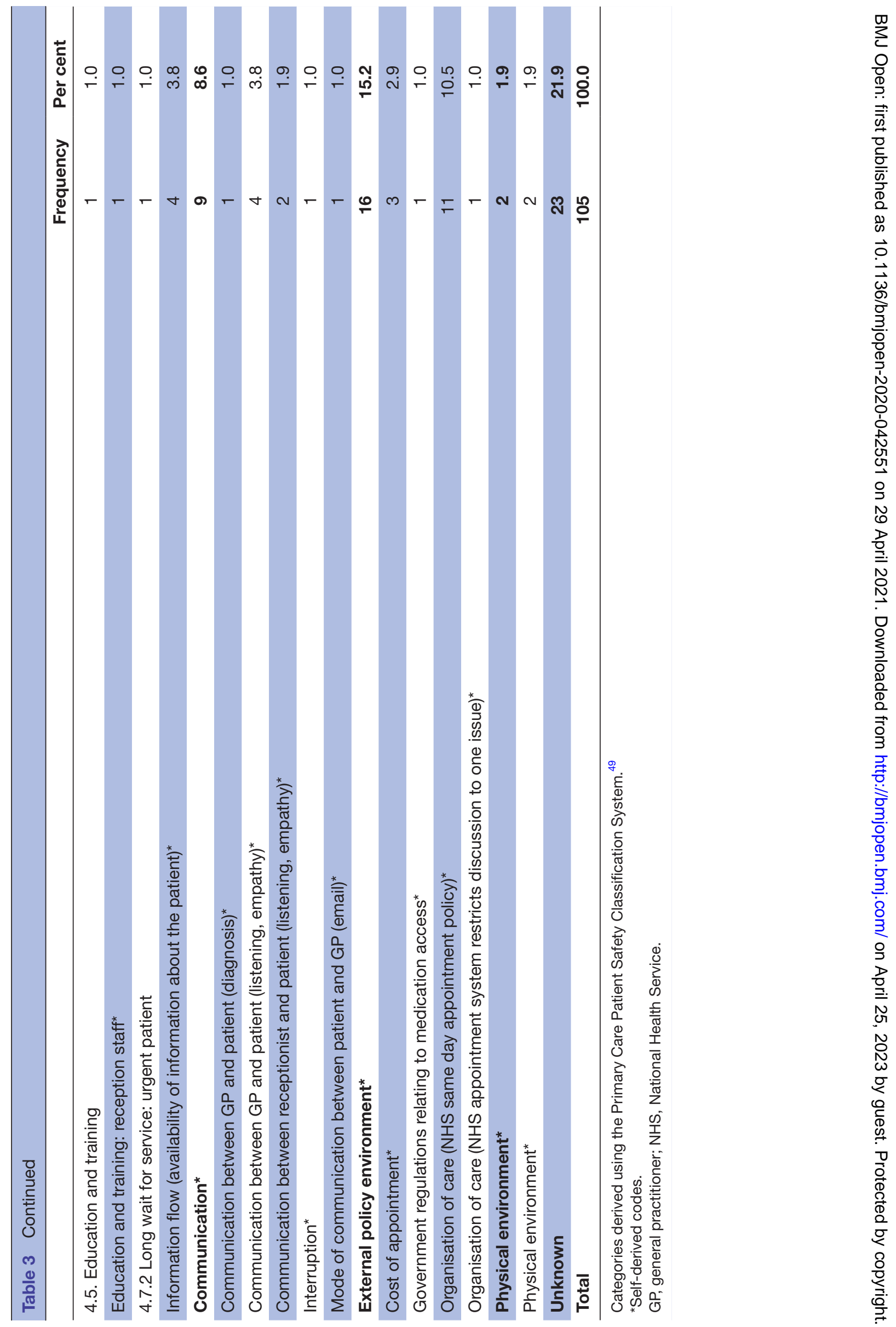


we were nearly turned away and told we could not be checked in to see the doctor as we were 2 minutes late. After some discussion and explaining why we were late they allowed us in (child needed to go to the toilet as we were walking out the door at home). (Study 2)

Moreover, staff factors was the second most commonly reported contributory factor to safety incidents. Inadequate skill set/knowledge was identified in $n=9(8.6 \%)$ of patient reports and was mainly associated with diagnosis and assessments of patients and junior/trainee physicians:

I came with a swollen leg because I had a DVT before. I considered that it could be another DVT. I was assured hundred percent it wasn't a DVT. A couple of days after I saw another doctor who sent me straight to hospital where confirmed it was a DVT. The doctor concerned was wrong in her diagnosis. Locum doctors should have more training with long-term patients and consider illnesses that might need treating at hospital. (Study 1)
There were three self-derived contributory factor categories developed during analysis: communication (definition: effectiveness of the exchange and sharing of information between primary-care staff and patients), external policy environment (definition: national primary care system, structures and policies that impact on the delivery of care and resources available) and physical environment (definition: features of the physical environment that help or hinder safe practice). ${ }^{35}$ Staff listening to the patient and showing empathy were key contributory factors within the communication category, and problems encountered with the UK's NHS same day appointment policy for study 1 patients $(n=11,10.5 \%)$ was a prominent theme in the external policy environment category.

The types of outcomes from the patient-reported safety incidents were classified across four categories (table 4). There was no reported patient outcome, or it was difficult to determine a clear patient outcome, for the majority of the incidents $(n=38,45.2 \%)$. Inconvenience to patients was the second most common outcome $(n=24,28.6 \%)$.

Table 4 Frequency and proportion of the safety incidents outcome by category

No outcome/unclear outcome

\begin{tabular}{rr} 
Frequency & Per cent \\
\hline 38 & 45.2 \\
26 & 31.0 \\
3 & 3.6 \\
9 & 10.7 \\
21 & 25.0 \\
1 & 1.2 \\
1 & 1.2 \\
1 & 1.2 \\
3 & 3.6 \\
1 & 1.2 \\
8 & 9.5 \\
1 & 1.2 \\
1 & 1.2 \\
\hline 4 & 4.8 \\
\hline 24 & 28.6 \\
\hline
\end{tabular}

0.2 No outcome described

10.7

0.4 unclear outcome/insufficient information to ascertain outcome

Patient clinical harm

1.1.13. General deterioration/progression of condition

1.1.18.1 Deep Vein Thrombosis (DVT)

1.1.26 Difficulty breathing

1.1.7 Discomfort/pain

1.2 Injury

1.3 Psychological/emotional distress

Depression*

Social isolation*

Unpleasant experience*

Inconvenience to patient (non-clinical)

9

2.1 Repeated tests/procedure/additional treatment

$2 \quad 2.4$

2.2 Delays in management (assessment or treatment)

2.4. Financial implication

7

2.5 Repeated visits to/from healthcare providers

$\begin{array}{rr}1 & 1.2 \\ 1 & 1.2 \\ 2 & 2.4 \\ 2 & 2.4 \\ 1 & 1.2 \\ 1 & 1.2 \\ 84 & 100.0\end{array}$

2.8 Hospital admission

2.9. Missed dose(s) of medication

Organisational inconvenience

3.6 Treating patient without sufficient information

Categories derived using the Primary Care Patient Safety Classification System. ${ }^{49}$

*Self-derived codes. 
This predominantly concerned delays in management or time spent on attempting to access care. Patient clinical harm was the third most common outcome $(n=21$, $25 \%)$. Psychological and emotional distress $(n=8,9.5 \%)$, and unpleasant experiences $(n=4,4.8 \%)$ were frequently reported outcomes:

When I was in desperate need of help advice/support I rang distraught, and nobody helped me. I was just transferred between staff (not Drs). I should have been referred to [telephone counselling service] or a mental health option. My usual Dr was not available. The staff would not listen to my requests to see anybody. Instead shuffled me around listened but missed any opportunity to help me. This was not a normal issue/occurrence for me. I WAS DISTRAUGHT! I NEEDED HELP. My mental health was not addressed. My friend was worried for me/my husband was worried for me. But I had to wait a week to see my Dr who cared for me \& referred me to a mental health specialist immediately. I have dealt with this clinic for 30 years. I could have hurt myself... They seriously let me down.... (Study 2)

\section{Preventability and seriousness of patient-reported safety incidents}

Of those patients that reported a safety incident in question $1, \mathrm{n}=27$ patients believed their safety incident could have been prevented $(71.1 \%)$ and half believed their safety incident to be extremely serious $(n=20,51.3 \%)$. There were $17(42.5 \%)$ patients who believed their safety incident was both extremely serious and preventable.

\section{Patient characteristics associated with reporting a safety incident}

There were no differences in terms of age or gender between patients who reported a safety incident and those who didn't, but patients who did report a safety incident were more likely to have visited the general practice more often (12 vs 7 visits, $\mathrm{p}=0.006$ ), and had a significantly lower mean PC PMOS scores (indicating poorer safety) (3.8 vs $4.2, \mathrm{p}<0.001$ ).

\section{DISCUSSION}

This study contributes to the growing research characterising the nature of patient-reported safety incidents in primary care. $5.3 \%$ of patients reported a safety incident over the preceding 12 months. The most frequent type of incident was administration incidents, most of which concerned delays in patients accessing a physician. The most common contributory factor to the safety incidents was organisation of care, predominantly challenges with continuity of care. There was no reported patient outcome, or it was difficult to determine a clear patient outcome for over one third of incidents, with inconvenience to patient being the second most common outcome.
The frequency of patient-reported safety incidents is lower compared with other primary care patientreported studies, ${ }^{27-34}$ but similar to studies using record review or staff reported safety incidents. ${ }^{54}$ The number of safety incidents may be an underestimate of the true prevalence of safety incidents in primary care for several reasons. First, patient-reported safety incidents are different or rarely overlap with incidents reported through other mechanisms (eg, staff reporting or record review) ${ }^{46}$ Consequently, using a combination of patient, staff and record review methods may more accurately determine the frequency of safety incidents. ${ }^{55}$ Second, the data collection methods, including questionnaire wording and mode of collection, may have limited the number of patient responses. The questionnaire relied on patient recall from the previous 12 months which may be challenging for some patients. Additionally, patients may have experienced a safety incident without knowing it. The open-ended question asking patients to report 'safety concerns or issues' without direct prompts such as 'medication error' or 'misdiagnosis', as used in other research studies, ${ }^{28-31} 33$ may have been too broad to elicit explicit safety incident experiences. Furthermore, $40 \% \quad(n=28)$ of the safety incidents were reported in the 'other comments' section of the questionnaire. This may be attributed to patient's different understanding and conceptualisation of patient safety in primary care when compared with secondary care. ${ }^{36}$ Third, although the questionnaire is anonymous, patients may still feel reluctant to judge or pass on negative comments about their healthcare providers. Lastly, the survey implemented in this study was self-completed without external facilitation from researchers or primary care staff. Survey facilitation has been shown to increase the frequency of incident reporting. ${ }^{46}$

The types of safety incidents that patients reported in this study were different to incidents that have been reported by staff or identified during record review studies. ${ }^{49} 54-56$ These large epidemiological studies and systematic reviews have classified communication, diagnosis and assessment, and medication errors as common incident types in primary care. Conversely, errors in administration, mainly access to care, was the most frequent patient-reported incident. While administration errors may be perceived as 'soft issues', ${ }^{57}$ these incidents are highly relevant to the patient care journey and may be considered as precursors to more serious safety incidents.

The types of contributory factors from the safety incidents were similar to what has been previously described in the literature. ${ }^{27} 293135-40$ Additionally, there were several contributory factors reported by patients that did not correspond to any available codes in the PISA system. These findings indicate that patients have a unique perspective on patient safety which could be utilised to develop a patient inclusive taxonomy for use in primary care. Such a taxonomy may further facilitate the identification of important learning and preventative action across an extensive range of incidents in primary care. ${ }^{50}$ 
The data concerning the outcomes from the safety incidents in many patient reports was lacking or unclear. Many safety incidents to do not result in patient harm, ${ }^{13}$ which may explain the low frequency of outcomes reported. When there was an outcome reported the most common was inconvenience to the patient and psychological and emotional distress. Previous research has shown that patients emphasise emotional harm more so than physical harm when describing the outcome of a patient safety incident. ${ }^{37}{ }^{58}$ Indeed being treated with dignity and respect is the foremost reported safety priority for patients in the literature, ${ }^{35375859}$ consequently, a high frequency of emotional harm was not unexpected. Until recently, only physical health outcomes were used to classify harm severity across many PISA systems. ${ }^{6061}$ The newly developed Primary Care Harm Severity Classification System by Cooper et al encompasses mild, moderate and severe psychological harm categories as well as physical harm outcomes. ${ }^{50}$ This definition will assist professionals, organisations and policy-makers to understand the true nature of healthcare-associated harm.

The patient-reported preventability and seriousness of the safety incidents were generally higher than what is described in the literature. Most studies were conducted in hospital settings and employed clinician/academic reviewers rather than patient self-reported data. ${ }^{14} 46486263$ The patient perspective of the preventability and seriousness of safety incidents is an additional safety intelligence measure that can be used by researchers, health professionals and policy-makers to further understand and support patients who have experienced a safety incident in primary care.

Frequent attenders and those with lower overall scores of safety on the PC PMOS (indicating poor safety experiences) were significantly more likely to report a safety incident. These findings should be interpreted with caution due to the small sample size. Nonetheless the results are corroborated by studies which have identified a range of patient characteristics associated with experiencing safety incidents in primary care. ${ }^{6465}$ Conversely, patient gender and age were not associated with experience of a safety incident. This finding is unable to be explained when compared with research showing that gender and age have been associated with increased likelihood of experiencing a safety incident. ${ }^{304-69}$ Identifying patients at risk of safety incidents is important for monitoring, assessing and error prevention efforts. ${ }^{13}$

It is worth noting that the survey used to collect the patient-reported safety incident data was not part of a formal incident reporting system. The survey was employed as a part of a suite of tools that are essential for primary care systems to learn from unsafe care and implement safety improvements. The impact of the patient-reported safety incidents from this study has been demonstrated through implementation of an innovative patient feedback on safety intervention. Primary care teams reviewed the patient-reported safety data and developed specific safety interventions which resulted in significantly improved patient safety scores. ${ }^{15}$
The cross-sectional study design may have been a limitation in this study. Longitudinal studies which track patients over time or qualitative studies may have elicited more in depth and rich data to accurately classify the incident type, contributory factor, level of harm and harm type for each safety incident. Due to the lack of data or detail in some of the patient reports we were not able to determine the level of harm associated with each outcome. ${ }^{50}$ Likewise, due to the small number of incidents further analysis investigating the association between type of incident and outcome was unable to be undertaken. As the PC PMOS was an anonymous survey, patients may have been able to report more than one safety incident if they visited their practice more than once during the recruitment period. However, the safety incidents reported by patients were perceived by the reviewer panel as separate and unique incidents. Furthermore, demographic information about patients who completed the PC PMOS compared with those who declined to participate was only available for study $2,{ }^{15}$ and limited information was collected in study $1 .^{41}$ As a result of this incomplete data, it is it is difficult to determine any differences between patients who chose to participate in the study compared with those who declined in terms of likelihood of experiencing and reporting a safety incident. Small differences between the two study settings (England and Australia) were observed for some contributory factors relating to the external policy context such as cost of appointment and same day appointment policies. Given that these contributory factors only made up $15 \%$ of the total factors reported, the authors believe that the majority of incident types and subsequent contributory factors were more generic and reflected a universal experience of patient safety in primary care across the two settings. These findings contribute to the growing evidence base examining the nature of patient-reported incidents in primary care.

\section{CONCLUSION}

The patient perspective can complement existing sources of information and provides another dimension to the patient safety in primary care research field. Simple patient surveys, like the one employed in this study, can generate useful feedback for practice teams to engage in error prevention and learning activities. Changes to questionnaire wording and provision of patient safety incident type examples may increase the quantity and quality of patient reports and should be assessed in future research.

\footnotetext{
Author affiliations

${ }^{1}$ School of Medicine, Deakin Rural Health, Deakin University Faculty of Health, Geelong, Victoria, Australia

${ }^{2}$ NIHR Greater Manchester Patient Safety Translational Research Centre, University of Manchester, Manchester, UK

${ }^{3}$ Division of Population Medicine, Cardiff University School of Medicine, Cardiff, UK ${ }^{4}$ Australian Institute of Health Innovation, Sydney, New South Wales, Australia ${ }^{5}$ Faculty of Health Sciences and Medicine, Bond University, Gold Coast, Queensland, Australia

${ }^{6}$ Division of Pharmacy and Optometry, The University of Manchester, Manchester, UK
} 
Correction notice This article has been corrected since it was published. The word 'primary care' has been removed from the name of the institution mentioned in affiliation 2 and the funding statement.

\section{Twitter Andrea L Hernan @andreahernan11}

Acknowledgements The authors acknowledge the practice staff and patients who participated in this study. The authors would also like to acknowledge the administrative support from Gillian Beard and Liz Jackway at Deakin Rural Health, Rahul Alam at the National Institute for Health Research (NIHR) Greater Manchester Primary Care Patient Safety Translational Research Centre and Stuart Hellard at Cardiff University. The authors would also like to thank the two patient representatives who assisted with coding the patient safety incident reports.

Contributors ALH conceived and designed the study. SJG contributed to the study design. AC-S, MM, PL and JH were members of the expert panel that helped form consensus on the coding. ALH and SJG were responsible for the data analysis and manuscript preparation. ALH created the first draft of the manuscript and was responsible for its revisions. WV conducted the statistical analysis. AC-S, MM, PL, $\mathrm{JH}$ and VV contributed to specific sections of the manuscript. All authors read and approved the final version of the manuscript.

Funding Study 1 was supported by the Western Alliance (Grant number: WA-733721). Study 2 was funded by the National Institute for Health Research (NIHR) Greater Manchester Patient Safety Translational Research Centre (Grant number: gmpstrc-2012-1).

Disclaimer The views expressed are those of the author(s) and not necessarily those of the NHS, the NIHR or the Department of Health.

\section{Competing interests None declared.}

Patient consent for publication Not required.

Ethics approval Ethical approval for study 1 was granted from NHS Health Research Authority (HRA) approval (project no. 16/SS/0096). Ethics approval for study 2 was granted from Deakin University Human Ethics Advisory Group, Faculty of Health (HEAG-H 175 2017).

Provenance and peer review Not commissioned; externally peer reviewed.

Data availability statement Data are available on reasonable request to the authors.

Supplemental material This content has been supplied by the author(s). It has not been vetted by BMJ Publishing Group Limited (BMJ) and may not have been peer-reviewed. Any opinions or recommendations discussed are solely those of the author(s) and are not endorsed by BMJ. BMJ disclaims all liability and responsibility arising from any reliance placed on the content. Where the content includes any translated material, BMJ does not warrant the accuracy and reliability of the translations (including but not limited to local regulations, clinical guidelines, terminology, drug names and drug dosages), and is not responsible for any error and/or omissions arising from translation and adaptation or otherwise.

Open access This is an open access article distributed in accordance with the Creative Commons Attribution Non Commercial (CC BY-NC 4.0) license, which permits others to distribute, remix, adapt, build upon this work non-commercially, and license their derivative works on different terms, provided the original work is properly cited, appropriate credit is given, any changes made indicated, and the use is non-commercial. See: http://creativecommons.org/licenses/by-nc/4.0/.

\section{ORCID iDs}

Andrea L Hernan http://orcid.org/0000-0003-4542-1186

Andrew Carson-Stevens http://orcid.org/0000-0002-7580-7699

\section{REFERENCES}

1 Auraaen A, Slawomirski L, Klazinga N. The economics of patient safety in primary and ambulatory care: flying blind. OECD health working papers no 106. Directorate for employment, labour and social Affairs, health division: organisation for economic co-operation and development, 2018.

2 Hall J, Peat M, Birks Y, et al. Effectiveness of interventions designed to promote patient involvement to enhance safety: a systematic review. BMJ Qual Saf 2010;19:e10-17.

3 Health Foundation. Involving patients in improving safety. London, UK: The Health Foundation, 2013.

4 Park M, Giap T-T-T. Patient and family engagement as a potential approach for improving patient safety: a systematic review. J Adv Nurs 2020;76:62-80.
5 Severinsson E, Holm AL. Patients' role in their own safety-a systematic review of patient involvement in safety. Open $\mathrm{J}$ Nurs 2015;05:642-53.

6 Sutton E, Eborall H, Martin G. Patient involvement in patient safety: current experiences, insights from the wider literature, promising opportunities? Public Management Review 2015;17:72-89.

7 Vincent C, Davis R. Patients and families as safety experts. CMAJ 2012;184:15-16.

8 World Health Organization. Patient engagement: technical series on safer primary care. Geneva: WHO, 2016.

9 Verstappen W, Gaal S, Bowie P, et al. A research agenda on patient safety in primary care. Recommendations by the LINNEAUS collaboration on patient safety in primary care. Eur J Gen Pract 2015;21 Suppl:72-7.

10 Donaldson LJ. The wisdom of patients and families: ignore it at our peril. BMJ Qual Saf 2015;24:603-4.

11 Lang S, Velasco Garrido M, Heintze C. Patients' views of adverse events in primary and ambulatory care: a systematic review to assess methods and the content of what patients consider to be adverse events. BMC Fam Pract 2016;17:6.

12 Lawton R, Armitage G. The role of the patient in clinical safety. London UK: Health Foundation, 2012.

13 Vincent C. Patient safety. 2nd ed. Oxford UK: Wiley-Blackwell BMJ books, 2010.

14 Lawton R, O'Hara JK, Sheard L, et al. Can patient involvement improve patient safety? a cluster randomised control trial of the patient reporting and action for a safe environment (PRASE) intervention. BMJ Qual Saf 2017;26:622-31.

15 Hernan AL, Giles SJ, Beks H, et al. Patient feedback for safety improvement in primary care: results from a feasibility study. BMJ Open 2020;10:e037887.

16 Cresswell KM, Panesar SS, Salvilla SA, et al. Global research priorities to better understand the burden of iatrogenic harm in primary care: an international Delphi exercise. PLoS Med 2013;10:e1001554.

17 Ensaldo-Carrasco E, Sheikh A, Cresswell K. Patient safety incidents in primary care dentistry in England and Wales: a mixed-methods study. Journal of Patient Safety 2020.

18 Young RS, Deslandes P, Cooper J, et al. A mixed methods analysis of lithium-related patient safety incidents in primary care. Ther Adv Drug Saf 2020;11:204209862092274.

19 Gibson R, MacLeod N, Donaldson LJ, et al. A mixed-methods analysis of patient safety incidents involving opioid substitution treatment with methadone or buprenorphine in community-based care in England and Wales. Addiction 2020;115:2066-76.

20 Omar A, Rees P, Cooper A, et al. Health and social care-associated harm amongst vulnerable children in primary care: mixed methods analysis of national safety reports. Arch Dis Child 2020;105:731-7.

21 Dinnen T, Williams H, Yardley S, et al. Patient safety incidents in advance care planning for serious illness: a mixed-methods analysis. BMJ Support Palliat Care 2019. doi:10.1136/ bmjspcare-2019-001824. [Epub ahead of print: 28 Aug 2019].

22 Williams H, Donaldson SL, Noble S, et al. Quality improvement priorities for safer out-of-hours palliative care: lessons from a mixedmethods analysis of a national incident-reporting database. Palliat Med 2019;33:346-56.

23 Cooper A, Edwards A, Williams H, et al. Sources of unsafe primary care for older adults: a mixed-methods analysis of patient safety incident reports. Age Ageing 2017;46:833-9.

24 Cooper J, Edwards A, Williams $\mathrm{H}$, et al. Nature of blame in patient safety incident reports: mixed methods analysis of a national database. Ann Fam Med 2017;15:455-61.

25 Rees P, Edwards A, Powell C, et al. Patient safety incidents involving sick children in primary care in England and Wales: a mixed methods analysis. PLoS Med 2017;14:e1002217.

26 Rees P, Edwards A, Panesar S, et al. Safety incidents in the primary care office setting. Pediatrics 2015;135:1027-35.

27 Hotvedt R, Førde OH. Doctors are to blame for perceived medical adverse events. A cross sectional population study. The Tromse study. BMC Health Serv Res 2013;13:46.

28 Kistler CE, Walter LC, Mitchell CM, et al. Patient perceptions of mistakes in ambulatory care. Arch Intern Med 2010;170:1480-7.

29 Mira JJ, Nebot C, Lorenzo S, et al. Patient report on information given, consultation time and safety in primary care. BMJ Qual Saf 2010;19:e33-4.

30 Panagioti M, Blakeman T, Hann M, et al. Patient-Reported safety incidents in older patients with long-term conditions: a large crosssectional study. BMJ Open 2017;7:e013524.

31 Ricci-Cabello I, Marsden KS, Avery AJ, et al. Patients' evaluations of patient safety in English general practices: a cross-sectional study. Br J Gen Pract 2017;67:e474-82. 
32 Schoen C, Osborn R, Doty MM, et al. Toward higher-performance health systems: adults' health care experiences in seven countries, 2007. Health Aff 2007;26:w717-34.

33 Solberg LI, Asche SE, Averbeck BM, et al. Can patient safety be measured by surveys of patient experiences? Jt Comm J Qual Patient Saf 2008;34:266-74.

34 Stocks SJ, Donnelly A, Esmail A, et al. Frequency and nature of potentially harmful preventable problems in primary care from the patient's perspective with clinician review: a population-level survey in Great Britain. BMJ Open 2018;8:e020952.

35 Hernan AL, Giles SJ, Fuller J, et al. Patient and carer identified factors which contribute to safety incidents in primary care: a qualitative study. BMJ Qual Saf 2015;24:583-93.

36 Hernan AL, Walker C, Fuller J, et al. Patients' and carers' perceptions of safety in rural general practice. Med J Aust 2014;201:S60-3.

37 Kuzel AJ, Woolf SH, Gilchrist VJ, et al. Patient reports of preventable problems and harms in primary health care. Ann Fam Med 2004;2:333-40.

38 Rhodes P, Campbell S, Sanders C, Trust SC. Trust, temporality and systems: how do patients understand patient safety in primary care? A qualitative study. Health Expect 2016;19:253-63.

39 Rhodes P, McDonald R, Campbell S, et al. Sensemaking and the co-production of safety: a qualitative study of primary medical care patients. Sociol Health IIIn 2016;38:270-85.

40 Ricci-Cabello I, Pons-Vigués $\mathrm{M}$, Berenguera $\mathrm{A}$, et al. Patients' perceptions and experiences of patient safety in primary care in England. Fam Pract 2016;33:535-42.

41 Giles SJ, Parveen S, Hernan AL. Validation of the primary care patient measure of safety (PC PMOS) questionnaire. BMJ Qual Saf 2019;28:389-96.

42 Hernan AL, Kloot K, Giles SJ, et al. Investigating the feasibility of a patient feedback tool to improve safety in Australian primary care: a study protocol. BMJ Open 2019;9:e027327.

43 Heistaro S, Janus E, Dunbar J. Greater green triangle risk factor study: limestone Coast and Corangamite Shire surveys (basic report. Greater Green Triangle University Department of Rural Health, Flinders and Deakin Universities: Warrnambool, 2007.

44 Wright J, Lawton R, O'Hara J. Chapter 6, learning from error: a comparative study of patient-reported patient safety incidents and existing sources of patient safety data. improving patient safety through the involvement of patients: development and evaluation of novel interventions to engage patients in preventing patient safety incidents and protecting them against unintended harm. Southampton (UK: NIHR Journals Library, 2016.

45 Armitage G, Moore S, Reynolds C, et al. Patient-Reported safety incidents as a new source of patient safety data: an exploratory comparative study in an acute hospital in England. $J$ Health Serv Res Policy 2018;23:36-43.

46 O'Hara JK, Armitage G, Reynolds C, et al. How might health services capture patient-reported safety concerns in a hospital setting? an exploratory pilot study of three mechanisms. BMJ Qual Saf 2017;26:42-53.

47 Bates DW, Cullen DJ, Laird N, et al. Incidence of adverse drug events and potential adverse drug events. Implications for prevention. ade prevention Study Group. JAMA 1995;274:29-34.

48 Gurwitz JH, Field TS, Harrold LR. Incidence and preventability of adverse drug events among older persons in the ambulatory setting. JAMA 2003;289:1107-16.

49 Carson-Stevens A, Hibbert P, Williams $\mathrm{H}$, et al. Characterising the nature of primary care patient safety incident reports in the England and Wales national reporting and learning system: a mixed-methods agenda-setting study for general practice. Health Serv Deliv Res 2016:4:1-76.
50 Cooper J, Williams $\mathrm{H}$, Hibbert P, et al. Classification of patient-safety incidents in primary care. Bull World Health Organ 2018;96:498-505.

51 Hibbert P, Runciman W, Deakin A. A recursive model of incident analysis. Adelaide: Australian Patient Safety Foundation, 2007.

52 Landis JR, Koch GG. The measurement of observer agreement for categorical data. Biometrics 1977;33:159-74.

53 Weissman JS, Schneider EC, Weingart SN, et al. Comparing patientreported Hospital adverse events with medical record review: do patients know something that hospitals do not? Ann Intern Med 2008;149:100-8.

54 Panesar SS, deSilva D, Carson-Stevens A, et al. How safe is primary care? A systematic review. BMJ Qual Saf 2016;25:544-53.

55 Esmail A. Measuring and monitoring safety: a primary care perspective. thought paper. London: The Health Foundation, 2013.

56 Makeham M, Pont L, Prgomet M, et al. Patient safety in primary healthcare: an evidence check review brokered by the sax Institute ( www.saxinstitute.org.au) for the Australian Commission on safety and quality in health care 2015 .

57 O'Hara JK, Isden R. Identifying risks and monitoring safety: the role of patients and citizens. Thought paper: The Health Foundation, 2013.

58 Sokol-Hessner L, Folcarelli PH, Sands KEF. Emotional harm from disrespect: the neglected preventable harm. BMJ Qual Saf 2015;24:550-3.

59 Lawton R, McEachan RRC, Giles SJ, et al. Development of an evidence-based framework of factors contributing to patient safety incidents in hospital settings: a systematic review. BMJ Qual Saf 2012;21:369-80.

60 World Health Organisation. Patient safety: International classification for patient safety (ICPs), 2012. Available: http://www.who.int/ patientsafety/implementation/taxonomy/en/index.html

61 Linnaeus-PC Collaboration. International taxonomy of medical errors in primary care - version 2. Washington, DC: The Robert Graham Center, 2002.

62 O'Hara JK, Reynolds C, Moore S, et al. What can patients tell us about the quality and safety of hospital care? findings from a UK multicentre survey study. BMJ Qual Saf 2018;27:673-82.

63 O'Hara JK, Lawton RJ, Armitage G, et al. The patient reporting and action for a safe environment (PRASE) intervention: a feasibility study. BMC Health Serv Res 2016;16:676.

64 Piccardi C, Detollenaere J, Vanden Bussche P, Bussche PV, et al. Social disparities in patient safety in primary care: a systematic review. Int J Equity Health 2018;17:114.

65 Ricci-Cabello I, Reeves D, Bell BG, et al. Identifying patient and practice characteristics associated with patient-reported experiences of safety problems and harm: a cross-sectional study using a multilevel modelling approach. BMJ Qual Saf 2017;26:899-907.

66 Wisniewski AM, Luczkiewicz DL, Servoss TJ, et al. What happens to orders written for older primary care patients? Fam Med 2012;44:252-8

67 Gaal S, Verstappen W, Wolters R, et al. Prevalence and consequences of patient safety incidents in general practice in the Netherlands: a retrospective medical record review study. Implementation Sci 2011;6:1-7.

68 Smits M, Huibers L, Kerssemeijer B, et al. Patient safety in out-ofhours primary care: a review of patient records. BMC Health Serv Res 2010;10:335.

69 Tsang C, Bottle A, Majeed A, et al. Adverse events recorded in English primary care: observational study using the general practice research database. Br J Gen Pract 2013;63:e534-42.

70 Carson-Stevens A, Hibbert P, Avery A, et al. A cross-sectional mixed methods study protocol to generate learning from patient safety incidents reported from general practice. BMJ Open 2015;5:e009079. 